\title{
Operational Simulation of LC Ladder Filter Using VDTA
}

\author{
Praveen Kumar, ${ }^{1}$ Neeta Pandey, ${ }^{2}$ and Sajal Kumar Paul ${ }^{1}$ \\ ${ }^{1}$ Department of Electronics Engineering, Indian School of Mines, Dhanbad, India \\ ${ }^{2}$ Department of Electronics and Communications, Delhi Technological University, Delhi, India \\ Correspondence should be addressed to Neeta Pandey; n66pandey@rediffmail.com
}

Received 29 June 2016; Revised 18 November 2016; Accepted 4 December 2016; Published 23 January 2017

Academic Editor: Jiun-Wei Horng

Copyright (C) 2017 Praveen Kumar et al. This is an open access article distributed under the Creative Commons Attribution License, which permits unrestricted use, distribution, and reproduction in any medium, provided the original work is properly cited.

\begin{abstract}
In this paper, a systematic approach for implementing operational simulation of LC ladder filter using voltage differencing transconductance amplifier is presented. The proposed filter structure uses only grounded capacitor and possesses electronic tunability. PSPICE simulation using $180 \mathrm{~nm}$ CMOS technology parameter is carried out to verify the functionality of the presented approach. Experimental verification is also performed through commercially available IC LM13700/NS. Simulations and experimental results are found to be in close agreement with theoretical predictions.
\end{abstract}

\section{Introduction}

Current mode approach has received a considerable attention in the last few years for analog signal processing applications due to their low power consumption, large dynamic range, higher frequency ranges of operation, better accuracy, higher slew rate, and less complexity. As a result, a large number of current mode active elements such as operational transconductance amplifier (OTA), current conveyor (CC), current controlled conveyor (CCC), current feedback amplifier (CFOA), operational transresistance amplifier (OTRA), differential voltage current conveyor (DVCC), current differencing buffered amplifier (CDBA), current differencing transconductance amplifier (CDTA), and voltage differencing transconductance amplifier (VDTA) are published. A literature review of such analog active block is presented in $[1,2]$. The VDTA is a recently proposed analog building block composed of two transconductance amplifiers and may be used to implement different analog processing application such as floating and grounded inductor simulation [3, 4], analog filter [5-10], and oscillators [11-13].

For the active simulation of higher-order LC ladder filter, mainly three methods exist, which are wave active method, topological simulation, and operational simulation. In wave active approach, a wave equivalent is developed for inductor in series branch and then it is configured for other passive components by making suitable connection [14-21]. Large numbers of active blocks are used in this approach. In the second method, topological simulation or element replacement method, the inductor of LC ladder structure is replaced by appropriate configured active elements [22, 23]. The drawback of this configuration is that a floating capacitor is generally required and this degrades the performance of the derived filter topology in high frequency application. In the third approach, operational simulation or leap-frog method [23-30], simulation is carried out for the operation of ladder rather than its component.

Literature survey reveals the operational simulation of ladder filter using operational amplifier (OA) and current controlled conveyor (CCCII) [24], OTA [25, 26], CC [27], multiple output second generation current controlled conveyor (MO-CCCII) [28], current feedback amplifier (CFA) [29], and CFOA [30]. This paper presents a systematic approach for operational simulation of LC ladder filter using voltage differencing transconductance amplifier (VDTA). The proposed operational simulation of LC ladder using VDTA has the following advantage over existing circuits:

(i) Lesser numbers of active blocks are used as compared to $[24,26,28-30]$.

(ii) There is no use of resistors in realization, while [25, $29,30]$ use both floating and grounded resistors and [27] uses only grounded resistors. 
(iii) Only grounded capacitors are used in proposed implementation, while $[25,29]$ use floating capacitors too.

(iv) Proposed operational simulation of LC ladder also possesses electronic tunability of cut-off frequency, while $[27,29,30]$ do not.

As an example, a fourth-order Butterworth low pass filter is simulated by outlined approach and the workability of the filter is confirmed through PSPICE simulation using $180 \mathrm{~nm}$ CMOS technology parameter. The functionality of the ladder filter is also tested experimentally through IC LM13700/NS.

\section{VDTA}

The voltage differencing transconductance amplifier is consisting of two transconductance amplifiers [5]. Figures 1 and 2 represent the symbolic representation and CMOS implementation of VDTA.

The port relationship of VDTA in matrix form is characterized by the following equation:

$$
\left[\begin{array}{c}
I_{Z} \\
I_{X+} \\
I_{X-}
\end{array}\right]=\left[\begin{array}{ccc}
g_{m i} & -g_{m i} & 0 \\
0 & 0 & g_{m o} \\
0 & 0 & -g_{m o}
\end{array}\right]\left[\begin{array}{c}
V_{P} \\
V_{N} \\
V_{Z}
\end{array}\right],
$$

where $g_{m i}$ and $g_{m o}$ are the input and output transconductance gain of VDTA. The input transconductance amplifier converts the input voltage difference $\left(V_{P}-V_{N}\right)$ into current at $Z$ terminal and the voltage developed at $Z$ terminal is converted into current at $X+$ and $X$ - terminal by output transconductance amplifier. In this paper, VDTA is used as an active analog building block because of

(i) the simple CMOS implementation of VDTA,

(ii) presence of two transconductance amplifiers giving resistorless realization,

(iii) the transconductance gain of VDTA which can vary via bias current, therefore providing the electronic tunability to designed filter.

\section{Operational Simulation Using VDTA}

The operational simulation method takes a different approach from topological simulation or wave active method, as it simulates the operation of ladder rather than its component [23]. The circuit equations and voltage-current relationship of each element are written using KVL and KCL. Then these equations are represented by block diagrams or signal flow graph. Each block represents some analog operation such as summation, integration, and subtraction. The final circuit is obtained by properly combining these blocks.

To explain the above statement, a fourth-order low pass Butterworth filter of Figure 3 has been taken as a prototype. The transfer function of this prototype filter can be expressed as

$$
\begin{aligned}
& \frac{V_{o}}{V_{\text {in }}} \\
& =\frac{R_{L}}{s^{4} C_{1} C_{2} L_{1} L_{2} R_{L}+s^{3}\left(C_{1} L_{1} L_{2}+C_{1} C_{2} L_{2} R_{s} R_{L}\right)+s^{2}\left(L_{1} C_{1} R_{L}+L_{1} C_{2} R_{L}+L_{2} C_{2} R_{L}+L_{2} C_{1} R_{s}\right)+s\left(R_{s} R_{L} C_{1}+R_{s} R_{L} C_{2}+L_{1}+L_{2}\right)+\left(R_{s}+R_{L}\right)} .
\end{aligned}
$$

To develop operational simulation in a systematic manner, consider the general ladder of Figure 4, where the series branch elements are labelled by admittance $Y_{i}$ and the shunt branch elements are labelled by impedance $Z_{i}$. The ladder of Figure 4 can be described by the voltage and current equation as in (3a), (3b), (3c), and (3d) as follows:

$$
\begin{aligned}
& I_{1}=Y_{1}\left(V_{\text {in }}-V_{2}\right), \\
& V_{2}=Z_{1}\left(I_{1}-I_{3}\right), \\
& I_{3}=Y_{2}\left(V_{2}-V_{o}\right), \\
& V_{o}=Z_{2}\left(I_{3}-I_{5}\right) ;
\end{aligned}
$$

assume $I_{5}=0$;

$$
\text { then } V_{o}=Z_{2} I_{3} \text {, }
$$

where

$$
Y_{1}=\frac{1}{R_{s}+s L_{1}}
$$

$$
\begin{aligned}
& Y_{2}=\frac{1}{s L_{2}}, \\
& Z_{1}=\frac{1}{s C_{1}}, \\
& Z_{2}=\frac{1}{s C_{2}+1 / R_{L}} .
\end{aligned}
$$

Both voltage and current terms are present in (3a), (3b), (3c), and (3d). This problem can be easily resolved by scaling these equations by a resistor $R_{V}$.

$$
\begin{aligned}
R_{V} I_{1} & =R_{V} Y_{1}\left(V_{\text {in }}-V_{2}\right) \Longrightarrow \\
V_{I 1} & =\frac{R_{V}}{R_{s}+s L_{1}}\left(V_{\text {in }}-V_{2}\right), \\
V_{2} & =\frac{Z_{1}}{R_{V}}\left(R_{V} I_{1}-R_{V} I_{3}\right) \Longrightarrow \\
V_{2} & =\frac{1}{s C_{1} R_{V}}\left(V_{I 1}-V_{I 3}\right),
\end{aligned}
$$




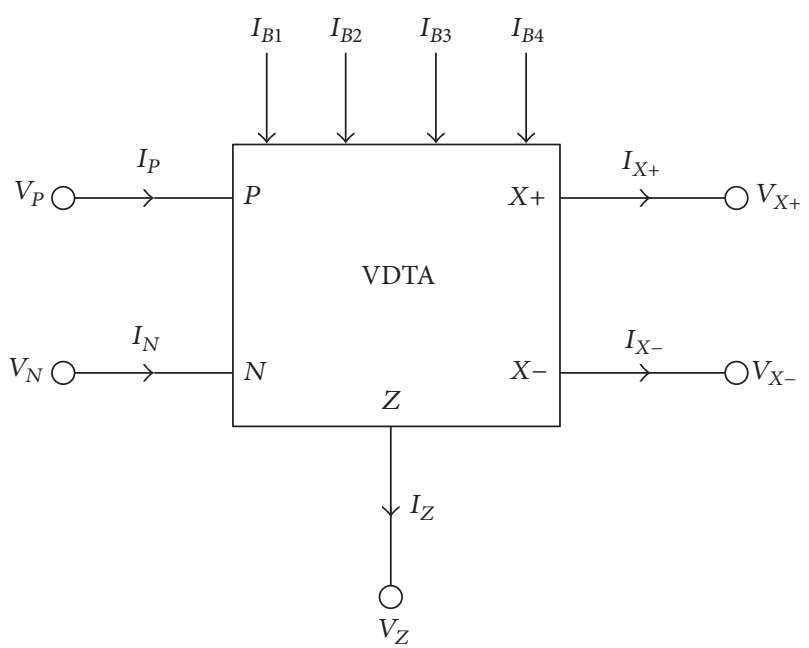

FIGURE 1: Symbolic representation of VDTA.

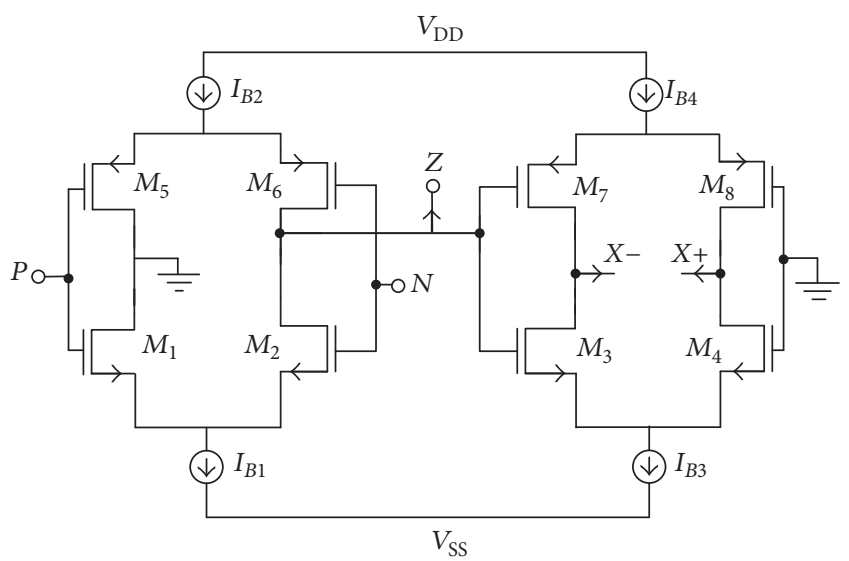

FIGURE 2: CMOS representation of VDTA.

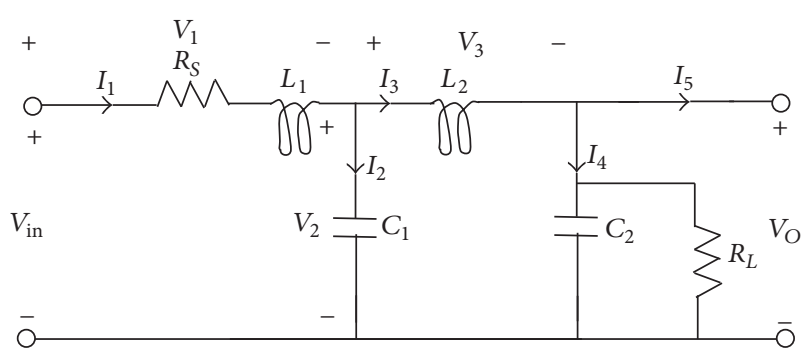

FIGURE 3: Fourth-order Butterworth low pass LC ladder.

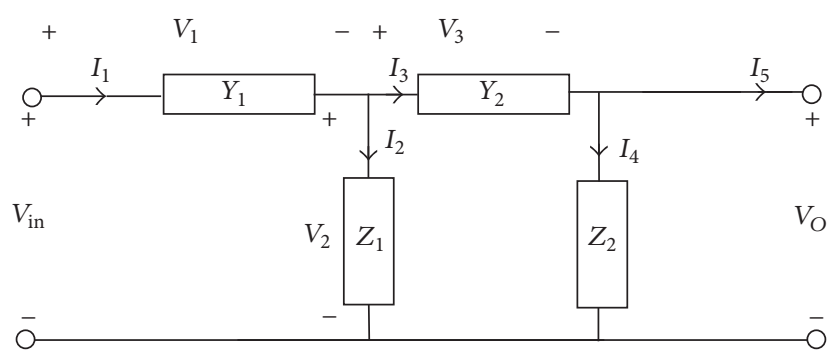

FIgURE 4: The ladder of Figure 3 with admittance in series arm and impedance in shunt arm.

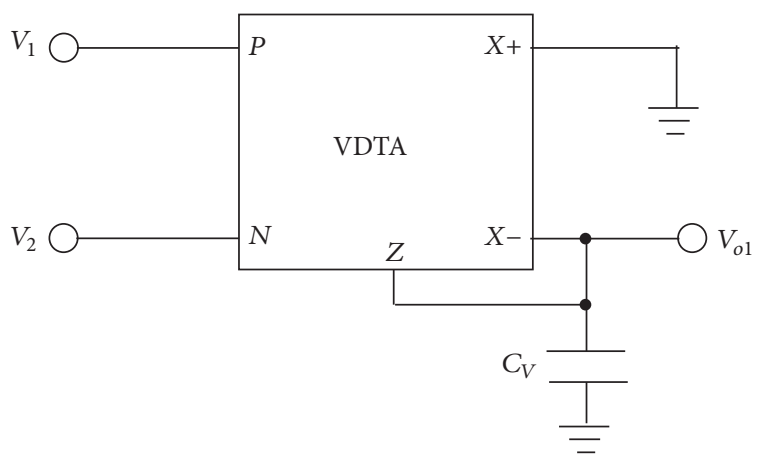

FIGURE 5: Lossy integrator using VDTA.

$$
\begin{aligned}
R_{V} I_{3} & =R_{V} Y_{2}\left(V_{2}-V_{o}\right) \Longrightarrow \\
V_{I 3} & =\frac{R_{V}}{s L_{2}}\left(V_{2}-V_{o}\right), \\
V_{o} & =\frac{Z_{2}}{R_{V}} R_{V} I_{3} \Longrightarrow \\
V_{o} & =\frac{1}{s C_{2} R_{V}+R_{V} / R_{L}} V_{I 3},
\end{aligned}
$$

where $V_{I 1}=R_{V} I_{1} ; V_{I 3}=R_{V} I_{3}$.

The subscript $I$ with voltages represents the fact that this voltage is derived from a current in the circuit.

Realization of (5a) to (5d) gives the operational simulation of prototype ladder filter of Figure 3. Implementation of $(5 \mathrm{a})$ and $(5 \mathrm{~d})$ requires lossy integrator, while implementation of (5b) and (5c) requires lossless integrator. The lossy and lossless integrator can be easily realized using VDTA as discussed in the following section.

3.1. Lossy Integration. The implementation of lossy integration using VDTA is shown in Figure 5. The expression for output voltage of lossy integrator can be written as

$$
V_{\mathrm{O} 1}=\frac{1}{1+s \tau}\left(V_{1}-V_{2}\right)
$$

where

$$
\left.\tau=\frac{C_{V}}{g_{m}} \quad \text { (with } g_{m i}=g_{m o}=g_{m}\right)
$$

3.2. Lossless Integrator. Lossless integrator can be implemented using VDTA as shown in Figure 6 and its output voltage expression is

$$
V_{o 2}=\frac{1}{s \tau}\left(V_{1}-V_{2}\right)
$$

Again

$$
\tau=\frac{C_{V}}{g_{m}} \quad\left(\text { with } g_{m i}=g_{m o}=g_{m}\right)
$$




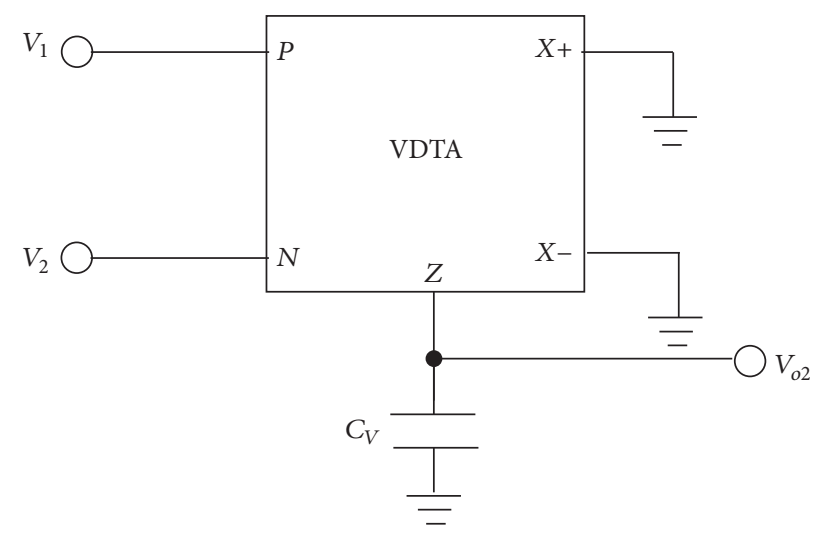

FIGURE 6: Lossless integrator using VDTA.

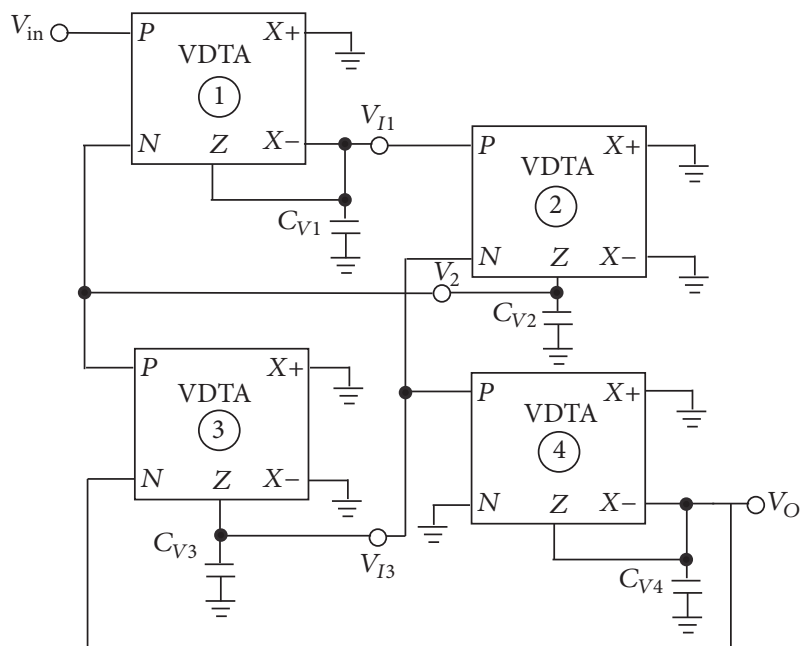

FIGURE 7: VDTA implementation of Figure 3 using operational simulation approach.

3.3. Complete Realization Using VDTA. With the help of lossy and lossless integrator of Figures 5 and 6, the complete realization of prototype 4 th-order filter using operational simulation approach is shown in Figure 7.

The value of capacitor used in VDTA 1 and VDTA 4 can be calculated by comparing (6a) and (6b) with (5a) and (5d) as follows.

From (6a) and (6b) and (5a),

$$
\begin{aligned}
\frac{R_{s}}{R_{V}} & =1 \Longrightarrow \\
R_{s} & =R_{V} .
\end{aligned}
$$

And $\tau=C_{V 1} / g_{m}=L_{1} / R_{V} \Rightarrow C_{V 1}=L_{1} g_{m} / R_{V}$.

Take the value of scaling resistor

$$
R_{V}=\frac{1}{g_{m}}
$$

Then

$$
C_{V 1}=L_{1} g_{m}{ }^{2}
$$

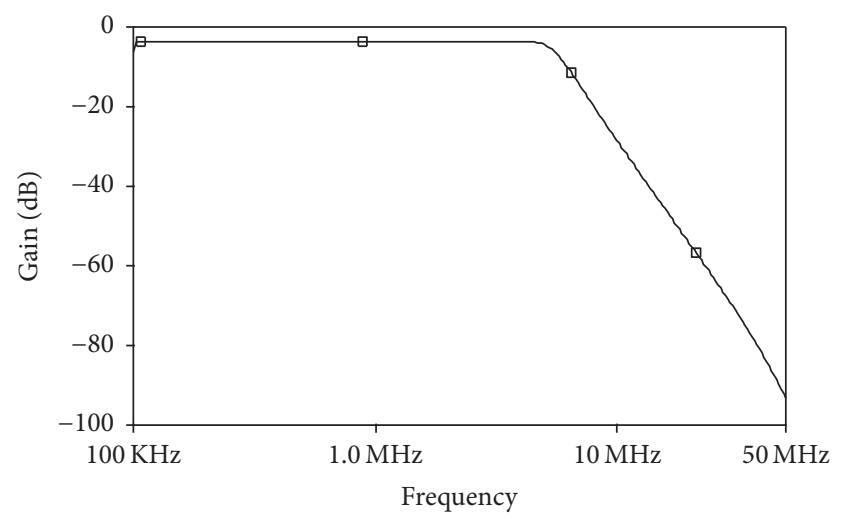

FIGURE 8: Simulated frequency response of 4th-order Butterworth low pass filter.

And from (6a) and (6b) and (5d)

$$
\begin{aligned}
\frac{R_{V}}{R_{L}} & =1 \Longrightarrow \\
R_{L} & =R_{V}, \\
\tau & =\frac{C_{V 4}}{g_{m}}=C_{2} R_{V} \Longrightarrow \\
C_{V 4} & =C_{2} .
\end{aligned}
$$

Similarly, the value of capacitor used in VDTA 2 and VDTA 3 can be calculated by comparing (7a) and (7b) with (5b) and (5c) as follows.

From (7a) and (7b) and (5b),

$$
\begin{aligned}
\tau & =\frac{C_{V 2}}{g_{m}}=C_{1} R_{V} \Longrightarrow \\
C_{V 2} & =C_{1} .
\end{aligned}
$$

And from (7a) and (7b) and (5c),

$$
\begin{aligned}
\tau & =\frac{C_{V 3}}{g_{m}}=\frac{L_{2}}{R_{V}} \Longrightarrow \\
C_{V 3} & =L_{2} g_{m}{ }^{2} .
\end{aligned}
$$

\section{Simulation}

The normalized component values of the prototype filter of Figure 3 are $R_{s}=1, L_{1}=.7654, C_{1}=1.8485, L_{2}=1.8485$, $C_{2}=.7654$, and $R_{L}=1$. The aspect ratio of various transistor used in CMOS implementation of VDTA is given in Table 1. The values of supply voltage and bias current for VDTA are $V_{\mathrm{DD}}=V_{\mathrm{SS}}=-0.9 \mathrm{~V}$ and $I_{B 1}=I_{B 2}=I_{B 3}=I_{B 4}=150 \mu \mathrm{A}\left(g_{m i}=\right.$ $\left.g_{m o}=g_{m}=627 \mu \mathrm{S}\right)$, respectively.

For cut-off frequency of $5 \mathrm{MHz}$, the values of capacitor used in Figure 7 can be calculated by (10), (12), (13), and (14) as $C_{V 1}=15.28 \mathrm{pF}, C_{V 2}=36.9 \mathrm{pF}, C_{V 3}=36.9 \mathrm{pF}$, and $C_{V 4}=$ $15.28 \mathrm{pF}$. Figure 8 shows the frequency response of the low pass fourth-order Butterworth filter. The simulated cut-off 


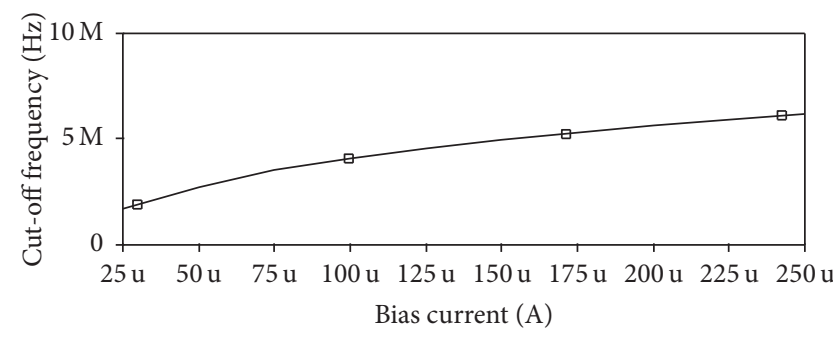

(a)

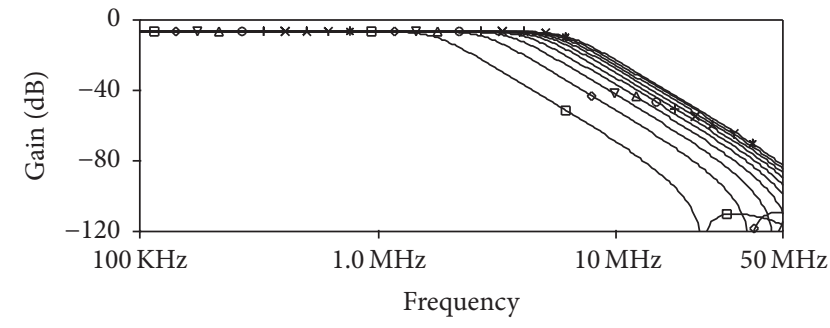

(b)

FIGURE 9: Electronic tuning demonstration. (a) Cut-off frequency variation with bias current. (b) Frequency response for various bias currents.

TABLE 1: Aspect ratio of various transistors used in CMOS implementation of VDTA.

\begin{tabular}{lc}
\hline Transistors & Aspect ratios $(W(\mu \mathrm{m}) / L(\mu \mathrm{m}))$ \\
\hline$M_{1}-M_{4}$ & $3.6 / .36$ \\
$M_{5}-M_{8}$ & $16.64 / .36$ \\
\hline
\end{tabular}
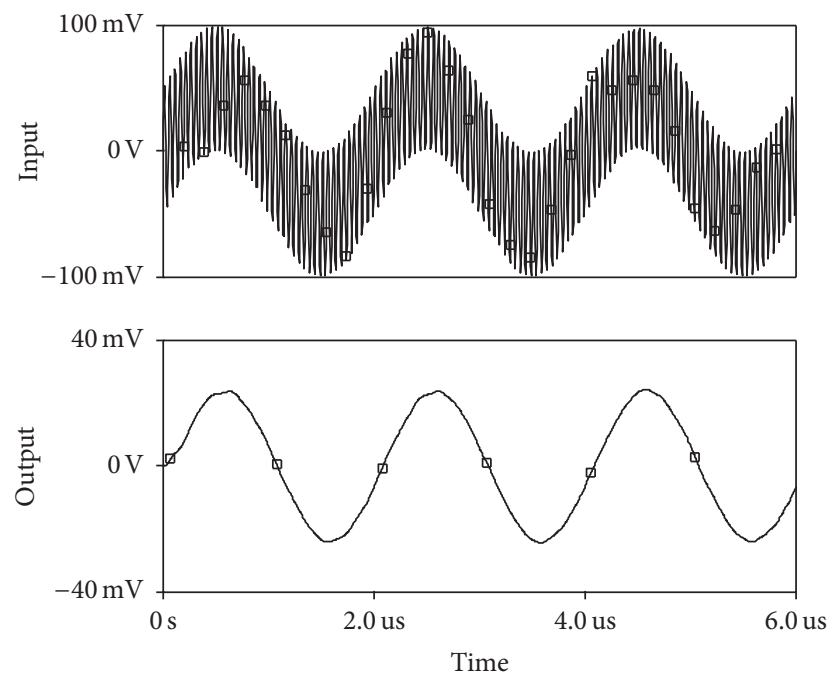

FIGURE 10: Transient response of input and output signals.

frequency is $4.99 \mathrm{MHz}$, which is very close to the theoretical cut-off frequency of $5 \mathrm{MHz}$. The electronic tunability of the filter through simulation is demonstrated in Figure 9 by varying bias current from $25 \mu \mathrm{A}$ to $250 \mu \mathrm{A}$. Time domain analysis is studied by applying two signals of frequency $500 \mathrm{KHz}$ and $20 \mathrm{MHz}$ and of magnitude $50 \mathrm{mV}$ at input. The transient response and its spectrum are shown in Figures 10 and 11, respectively. The proposed filter structure is also tested for total harmonic distortion at output and it is found that it is within acceptable limit of $3 \%$ up to $600 \mathrm{mV}$ p-p signal of frequency $1 \mathrm{MHz}$ as shown in Figure 12.

Noise analysis is also carried out for the proposed circuit by determining noise at output of the filter through simulation. The output noise variation within pass band frequencies is depicted in Figure 13 which shows that noise is in acceptable limit of nanovolt range. To examine effect of
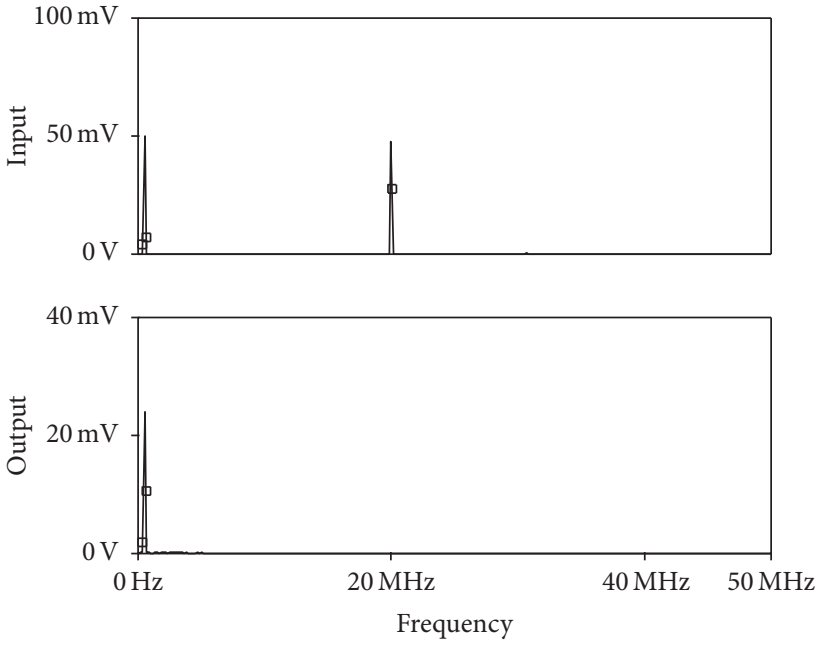

FIGURE 11: Frequency spectrum of input and output signals.

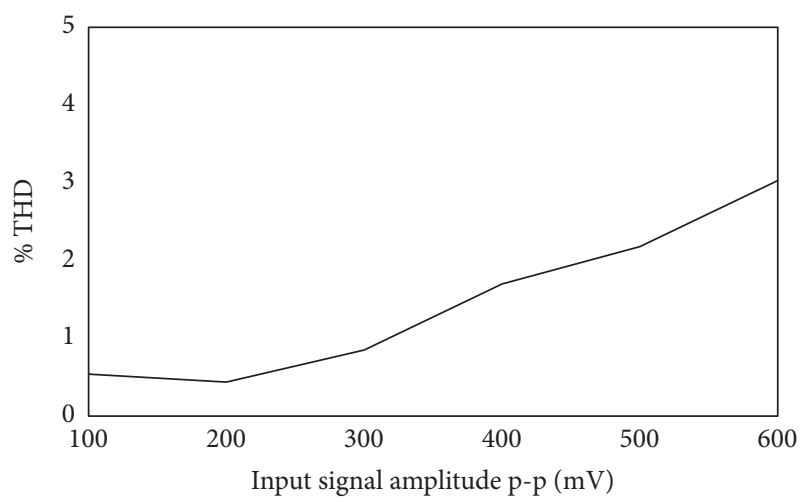

FIGURE 12: \% THD variation with p-p input signal amplitude.

temperature variation on proposed filter circuit, the circuit is simulated at five different temperatures, $10^{\circ} \mathrm{C}, 25^{\circ} \mathrm{C}, 27^{\circ} \mathrm{C}$, $50^{\circ} \mathrm{C}$, and $100^{\circ} \mathrm{C}$, and the results are depicted in Figure 14. The values of cut-off frequency for these temperatures are listed in Table 2. It is observed that cut-off frequency shifts towards lower frequencies as temperature decreases. This is due to the fact that the transconductance decreases with increases in temperature due to decrease in mobility. This shifting in cut-off frequency can be compensated through bias current 


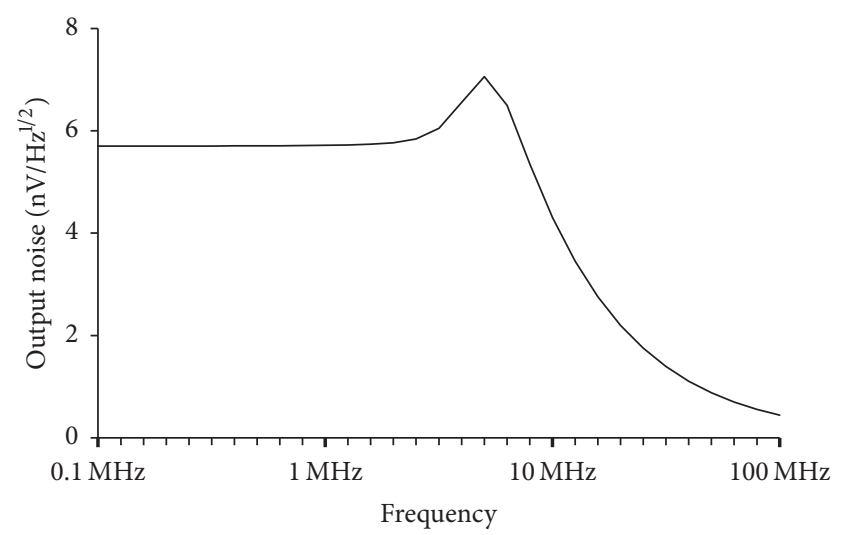

FIGURE 13: Output noise variation of proposed filter with frequency.

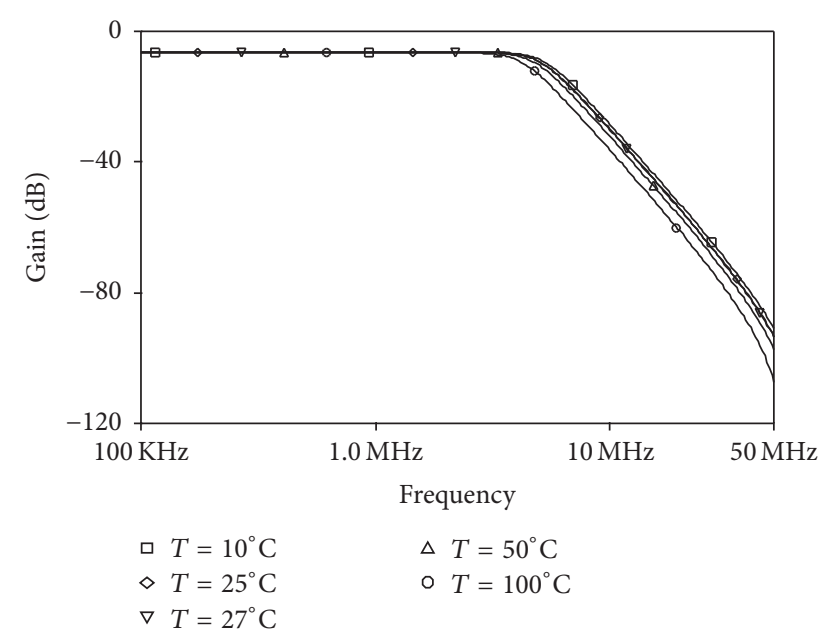

FIGURE 14: Demonstration of effect of temperature on proposed filter.

TABLE 2: Cut-off frequency at various temperatures.

\begin{tabular}{lc}
\hline Temperature & Cut-off frequency \\
\hline $10^{\circ} \mathrm{C}$ & $5.2 \mathrm{MHz}$ \\
$25^{\circ} \mathrm{C}$ & $5 \mathrm{MHz}$ \\
$27^{\circ} \mathrm{C}$ & $4.98 \mathrm{MHz}$ \\
$50^{\circ} \mathrm{C}$ & $4.7 \mathrm{MHz}$ \\
$100^{\circ} \mathrm{C}$ & $4.17 \mathrm{MHz}$ \\
\hline
\end{tabular}

variation from $104 \mu \mathrm{A}$ (for $f_{0}=4.17 \mathrm{MHz}$ at $100^{\circ} \mathrm{C}$ ) to $164 \mu \mathrm{A}$ (for $f_{0}=5.2 \mathrm{MHz}$ at $10^{\circ} \mathrm{C}$ ).

All the key parameters of the proposed filter structure are summarized in Table 3. The total power dissipated and output noise in simulation of the prototype filter are $2.16 \mathrm{~mW}$ and 5.7 $\times 10^{-9} \mathrm{~V} / \mathrm{Hz}^{1 / 2}$, while simulated values of these parameters for the VDTA implementation of the same-order filter using wave active method are $6.48 \mathrm{~mW}$ and $1.65 \times 10^{-8} \mathrm{~V} / \mathrm{Hz}^{1 / 2}$ [20].

Experimental verification is carried out for proposed circuit through commercially available IC LM13700/NS. The

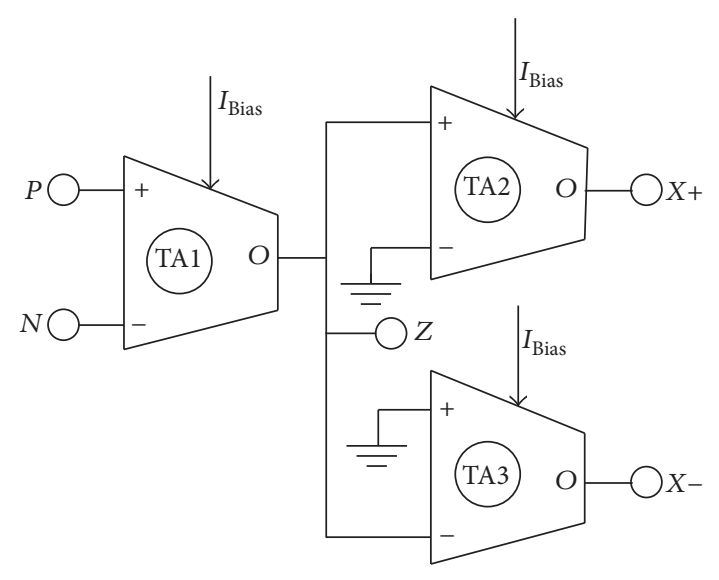

FIGURE 15: VDTA implantation using OTA.

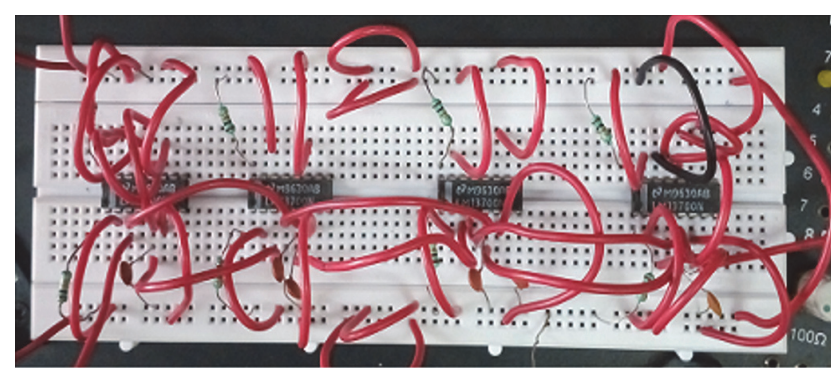

FIgURE 16: Bread-boarded circuit of Figure 7.

TABLE 3: Key parameters of simulated 4th-order low pass ladder filter.

\begin{tabular}{lc}
\hline Bias current & $150 \mu \mathrm{A}$ \\
VDTA transconductance, $g_{m}$ & $627 \mu \mathrm{S}$ at bias current of $150 \mu \mathrm{A}$ \\
Theoretical cut-off frequency & $5 \mathrm{MHz}$ \\
Simulated cut-off frequency & $4.99 \mathrm{MHz}$ \\
Roll-off rate & $80 \mathrm{~dB} / \mathrm{decade}$ \\
Total power consumption & $2.16 \mathrm{~mW}$ \\
Total output noise voltage & $5.7 \mathrm{nV} / \mathrm{Hz}^{1 / 2}$ \\
$\%$ THD & $<3 \%$ for input signal up to $600 \mathrm{mV} \mathrm{p}$-p \\
\hline
\end{tabular}

VDTA implementation using IC LM13700/NS is shown in Figure 15. The circuit of Figure 7 is bread-boarded as shown in Figure 16 for experimental testing. Supply voltage of $\pm 15 \mathrm{~V}$ is used. The bias current of $1.35 \mathrm{~mA}$ is set to obtain the transconductance of $24.89 \mathrm{~mA} / \mathrm{V}$. The capacitor values are selected as $C_{v 1}=C_{v 4}=10 \mathrm{nF}$ and $C_{v 2}=C_{v 3}=25 \mathrm{nF}$ for cutoff frequency of $303 \mathrm{kHz}$. The measured magnitude response along with simulated response is depicted in Figure 17. The experimental cut-off frequency is observed to be $292 \mathrm{kHz}$.

\section{Conclusion}

The paper presents a systematic methodology for active implementation of operational simulation of LC ladder filter. To explain the outlined approach, a 4th-order Butterworth 


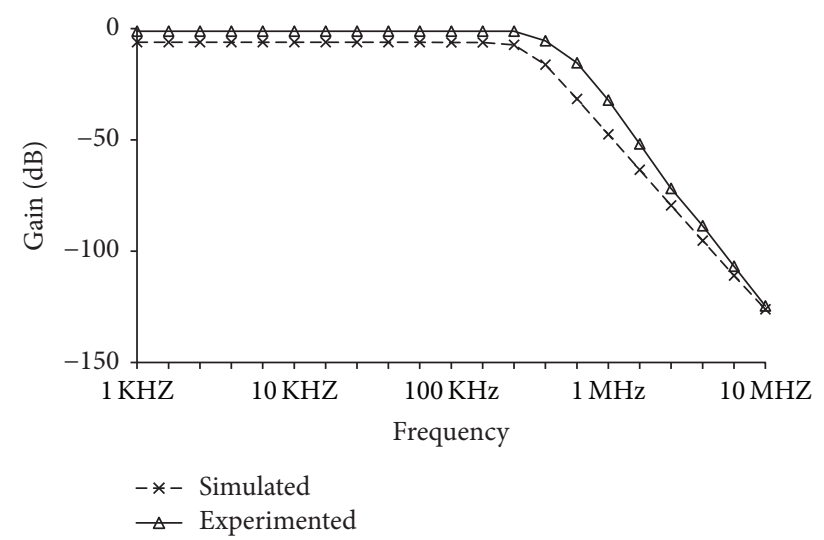

FIGURE 17: Simulated and experimented magnitude response of 4thorder low pass filter.

filter is taken as prototype, and, for active implementation, VDTA is used as an analog building block. The proposed implementation is resistorless and uses only grounded capacitors, which is suitable for IC implementation. The proposed structure also possesses electronic tunability of cut-off frequency. Workability of the proposed implementation is verified through PSPICE simulation using $180 \mathrm{~nm}$ TSMC technology parameters. The functionality of proposed LC ladder is also verified experimentally through IC LM13700/NS.

\section{Competing Interests}

The authors declare that they have no competing interests.

\section{References}

[1] K. K. Abdalla, D. R. Bhaskar, and R. Senani, "A review of the evolution of current-mode circuits and techniques and various modern analog circuit building blocks," Nature and Science, vol. 10, no. 10, 2012.

[2] D. Biolek, R. Senani, V. Biolkova, and Z. Kolka, "Active elements for analog signal processing: classification, review, and new proposals," Radioengineering, vol. 17, no. 4, pp. 15-32, 2008.

[3] D. Prasad and D. R. Bhaskar, "Grounded and floating inductance simulation circuits using VDTAs," Circuits and Systems, vol. 3, no. 4, pp. 342-347, 2012.

[4] W. Tangsrirat and S. Unhavanich, "Voltage differencing transconductance amplifier-based floating simulators with a single grounded capacitor," Indian Journal of Pure and Applied Physics, vol. 52, no. 6, pp. 423-428, 2014.

[5] A. Yeşil, F. Kaçar, and H. Kuntman, "New simple CMOS realization of voltage differencing transconductance amplifier and its RF filter application," Radioengineering, vol. 20, no. 3, pp. 632-637, 2011.

[6] A. Yeşil and F. Kaçar, "Electronically tunable resistorless mixed mode biquad filters," Radioengineering, vol. 22, no. 4, pp. 10161025, 2013.

[7] J. Satansup and W. Tangsrirat, "Compact VDTA-based currentmode electronically tunable universal filters using grounded capacitors," Microelectronics Journal, vol. 45, no. 6, pp. 613-618, 2014.
[8] D. Prasadl, D. R. Bhaskar, and M. Srivastava, "Universal voltagemode biquad filter using voltage differencing transconductance amplifier," Indian Journal of Pure and Applied Physics, vol. 51, no. 12, pp. 864-868, 2013.

[9] J. Satansup, T. Pukkalanun, and W. Tangsrirat, "Electronically tunable current-mode universal filter using VDTAs and grounded capacitors," in Proceedings of the International MultiConference of Engineers and Computer Scientists (IMECS '13), pp. 647-650, Hong Kong, China, March 2013.

[10] A. Uygur and H. Kuntman, "DTMOS-based 0.4V ultra lowvoltage low-power VDTA design and its application to EEG data processing," Radioengineering, vol. 22, no. 2, pp. 458-466, 2013.

[11] D. Prasad, M. Srivastava, and D. R. Bhaskar, "Electronically controllable fully-uncoupled explicit current-mode quadrature oscillator using VDTAs and grounded capacitors," Circuits and Systems, vol. 4, no. 2, pp. 169-172, 2013.

[12] D. Prasad and D. R. Bhaskar, "Electronically Controllable Explicit Current Output Sinusoidal Oscillator Employing Single VDTA," ISRN Electronics, vol. 2012, Article ID 382560, 5 pages, 2012.

[13] R. Sotner, J. Jerabek, N. Herencsar, J. Petrzela, K. Vrba, and Z. Kincl, "Linearly tunable quadrature oscillator derived from LC Colpitts structure using voltage differencing transconductance amplifier and adjustable current amplifier," Analog Integrated Circuits and Signal Processing, vol. 81, no. 1, pp. 121-136, 2014.

[14] I. Haritantis, A. Constantinides, and T. Deliyannis, "Wave active filter," Proceedings of the Institution of Electrical Engineers, vol. 123, no. 7, pp. 676-682, 1976.

[15] K. Georgia and P. Costas, "Modular filter structures using CFOA," Radio Engineering, vol. 19, no. 4, pp. 662-666, 2010.

[16] N. Pandey and P. Kumar, "Realization of resistorless wave active filter using differential voltage current controlled conveyor transconductance amplifier," Radioengineering, vol. 20, no. 4, pp. 911-916, 2011.

[17] N. Pandey, P. Kumar, and J. Choudhary, "Current controlled differential difference current conveyor transconductance amplifier and its application as wave active filter," ISRN Electronics, vol. 2013, Article ID 968749, 11 pages, 2013.

[18] M. Bothra, R. Pandey, N. Pandey, and S. K. Paul, "Operational trans-resistance amplifier based tunable wave active filter," Radioengineering, vol. 22, no. 1, pp. 159-166, 2013.

[19] H. Singh, K. Arora, and D. Prasad, "VDTA-based wave active filter," Circuits and Systems, vol. 5, no. 5, pp. 124-131, 2014.

[20] N. Pandey, P. Kumar, and S. K. Paul, "Voltage differencing transconductance amplifier based resistorless and electronically tunable wave active filter," Analog Integrated Circuits and Signal Processing, vol. 84, no. 1, pp. 107-117, 2015.

[21] H. Wupper and K. Meerkotter, "New active filter synthesis based on scattering parameters," IEEE Transaction on Circuit and System, vol. 22, no. 7, pp. 594-602, 1975.

[22] A. A. M. Shkir, "10kHz, lpw power, 8 th order eliptic bandpass filter employing CMOS VDTA," International Journal of Enhanced Research in Science Technology \& Engineering, vol. 4, no. 1, pp. 162-168, 2015.

[23] M. E. Van Valkenburg and R. Shaumann, Design of Analog Filters, Oxford University Press, Oxford, UK, 2001.

[24] Y. Xi and H. Peng, "Realization of lowpass and bandpass leapfrog filters using OAs and CCCIIs," in Proceedings of the International Conference on Management and Service Science (MASS '09), Wuhan, China, September 2009. 
[25] M. V. Katageri, M. M. Mutsaddi, and R. S. Mathad, "Comparative study of LC ladder active filter using OTA and current conveyor," International Journal of Advanced Computer and Mathematical Sciences, vol. 3, no. 3, pp. 321-325, 2012.

[26] R. Schaumann, "Simulating lossless ladders with transconductance-C circuits," IEEE Transactions on Circuits and Systems II: Analog and Digital Signal Processing, vol. 45, no. 3, pp. 407-410, 1998.

[27] V. Novotny and K. Vrba, "LC ladder filter emulation by structures with current conveyor," in Proceedings of the 4th WSEAS International Conference on Signal Processing, Computational Geometry \& Artificial Vision (ISCGAV '04), Tenerife, Spain, December 2004.

[28] A. Câmpeanu and J. Gal, "LC-ladder filters emulated by circuits with current controlled conveyors and grounded capacitors," in Proceedings of the International Symposium On Signals, Circuits and Systems (ISSCS '07), vol. 2, Iaşi, Romania, July 2007.

[29] T. S. Rathore and U. P. Khot, "CFA-based grounded-capacitor operational simulation of ladder filters," International Journal of Circuit Theory and Applications, vol. 36, no. 5-6, pp. 697-716, 2008.

[30] P. K. Sinha, A. Saini, P. Kumar, and S. Mishra, "CFOA based low pass and high pass ladder filter-a new configuration," Circuits and Systems, vol. 5, no. 12, pp. 293-300, 2014. 


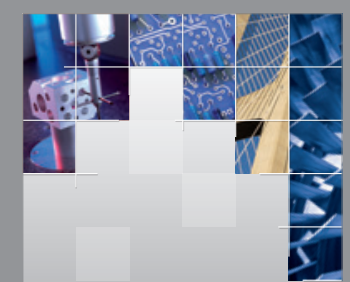

\section{Enfincering}
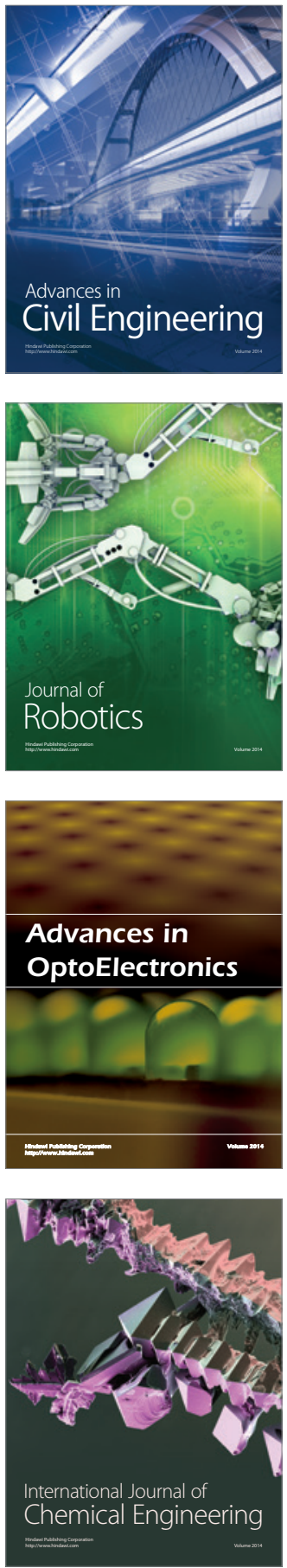

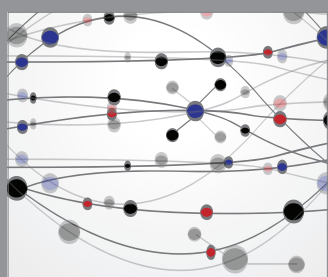

The Scientific World Journal

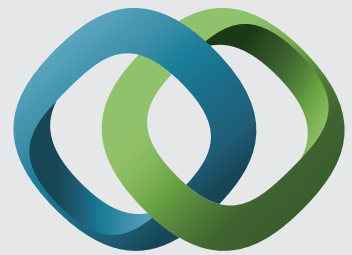

\section{Hindawi}

Submit your manuscripts at

https://www.hindawi.com
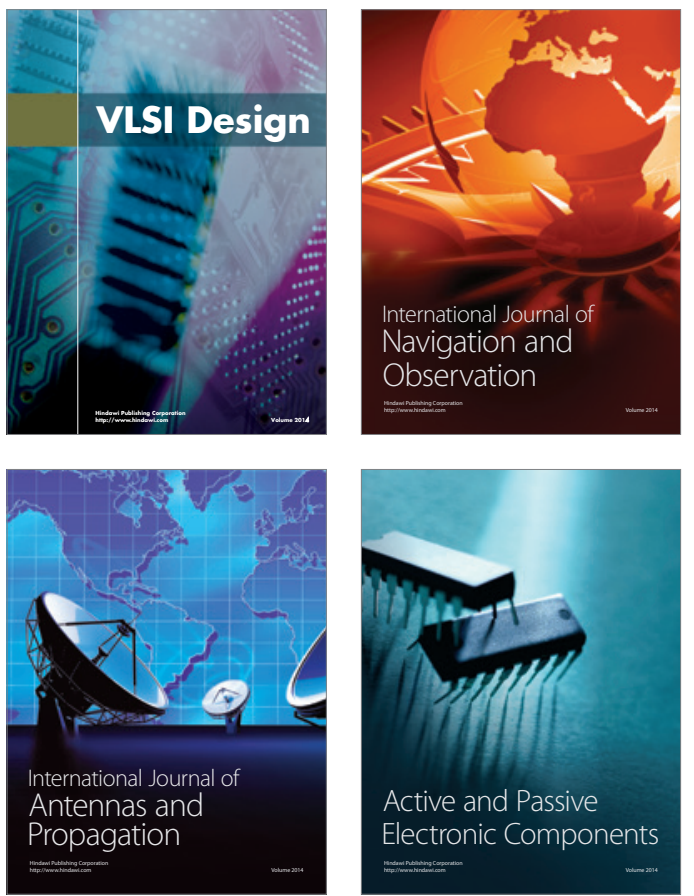
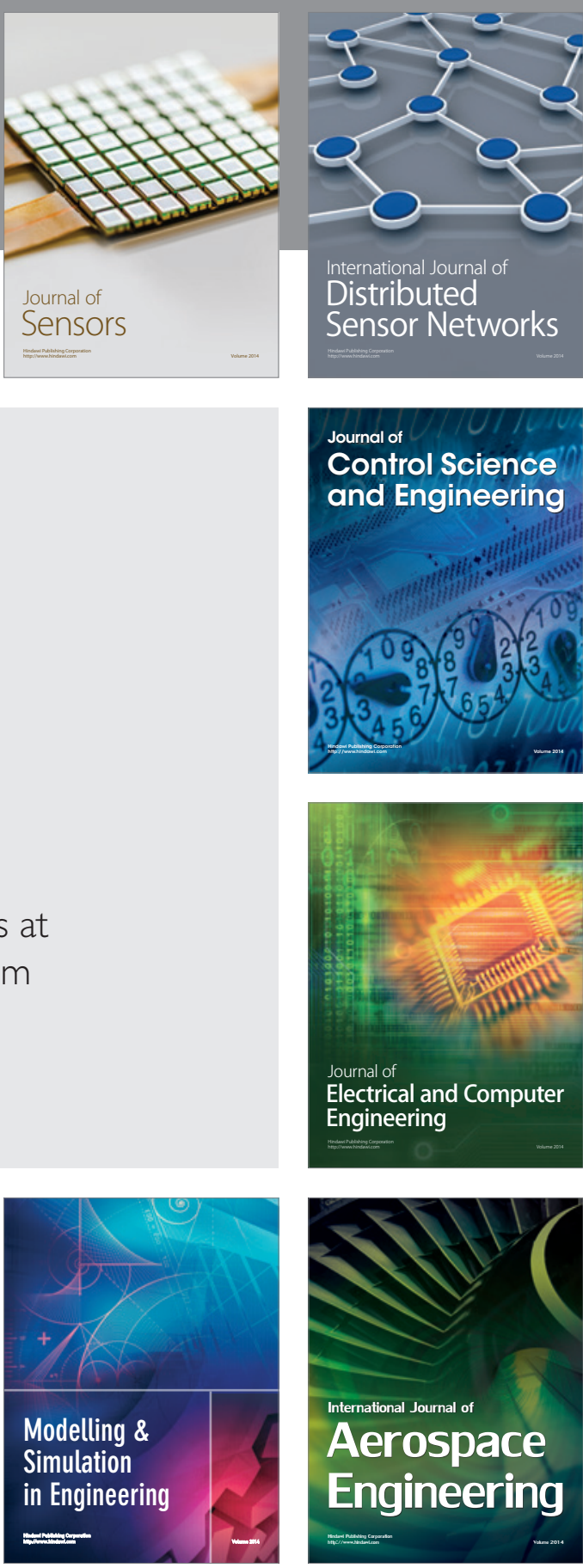

International Journal of

Distributed

Sensor Networks

$-$

Joumal of

Control Science

and Engineering
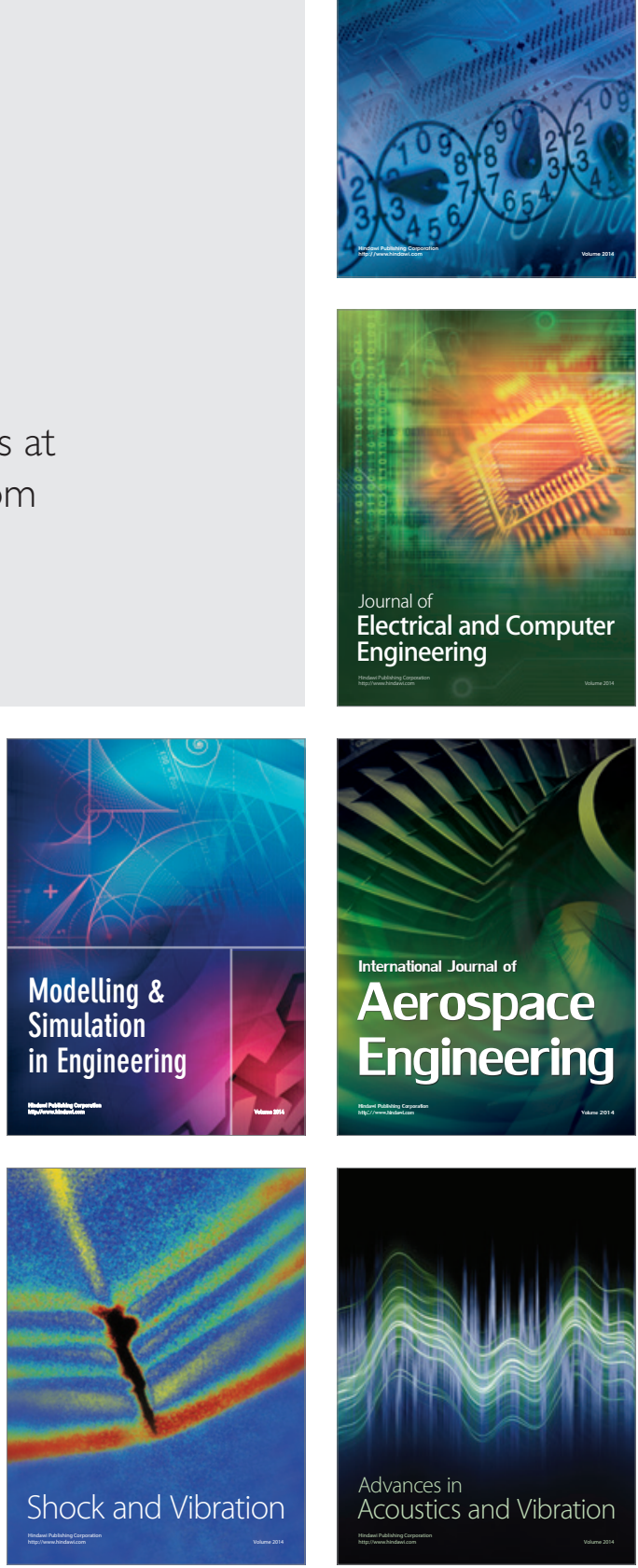